\title{
Perícia contábil: A percepção dos magistrados de primeira instância na comarca de Gurupi-TO, frente a relevância das perícias técnicas realizadas por peritos contadores nas demandas judiciais.
}

\section{Accounting expertise: The perception of the first instance magistrates in the commerce of gurupi-to, freight the relevance of the technical expertise performed by expert accountants in the judicial demands}

Eliane Lima Ramos ${ }^{1}$, Kátia Alves Rodrigues², Alessandra Martins Correia ${ }^{3}$

\section{RESUMO}

A Perícia Contábil, tem se destacado no atual cenário econômico-financeiro, por possuir um procedimento que exerce exame, vistoria e avaliação, utilizando de cálculos, na maior parte, sendo realizada por profissionais da área de Ciências Contábeis. O presente estudo tem como objetivo principal demonstrar a percepção dos Magistrados de primeira instância na comarca de Gurupi-TO, no que tange a relevância das Perícias técnicas realizadas por Peritos Contadores nas demandas judiciais. Quanto a metodologia, este estudo caracteriza-se como uma pesquisa qualitativa, esse tipo de pesquisa possui um caráter exploratório, sendo a pesquisa, dividida em quatro etapas: na fase inicial, com à formação do referencial teórico, para a base teórica para a pesquisa, segunda etapa, elaboração do instrumento de pesquisa, terceira etapa realizada a pesquisa de campo, com a coleta de dados, na quarta fase ocorreu a análise dos dados, com resultados e discursos. Os resultados desta pesquisa afirmam a importância de um profissional, tal como o Perito Contador, com aptidão, destreza e conhecimentos peculiares que possa elucidar questões em processo que requer peritos, para o desfecho de questões judiciais.

Palavras-chave: Contabilidade, Perícia Contábil, Magistrados.

\section{ABSTRACT}

Accounting Expertise has stood out in the current economic-financial scenario, as it has a procedure that exercises examination, inspection and evaluation, using calculations, mostly, performed by professionals in the area of Accounting Sciences. The main objective of this study is to demonstrate the perception of first instance magistrates in the district of Gurupi-TO, with regard to the relevance of technical expertise carried out by expert accountants in judicial demands. As for the methodology, this study is characterized as a qualitative research, this type of research has an exploratory character, the research being divided into four stages: in the initial phase, with the formation of the theoretical framework, for the theoretical basis for the research, second stage, elaboration of the research instrument, third stage carried out the field research, with data collection, in the fourth phase the data analysis occurred, with results and speeches. The results of this research affirm the importance of a professional, such as the Expert Accountant, with aptitude, dexterity and peculiar knowledge who can elucidate issues in a process that requires experts, for the outcome of judicial issues.

Discente do Curso de Ciências Contábeis da Universidade Gurupi- UNIRG.

E-mail: 035eliane@gmail.com

${ }^{2}$ Discente do Curso de Ciências Contábeis e Bacharel em Administração da Universidade Gurupi- UNIRG, Especialista em Recursos Humanos - UNINTER. Cursando MBA em Contabilidade, Auditoria e Gestão Tributária IPOG.

E-mail: katia.gpi@hotmail.com

${ }^{3}$ Docente Mestre do Curso de Ciências Contábeis da Universidade de Gurupi-UNIRG.

E-mail:

Keywords: Accounting, Accounting Expertise, Magistrates. 


\section{INTRODUÇAOO}

Em um dos países, com código tributário tão complexo como o Brasil, os profissionais contábeis têm uma função fundamental nesse panorama. "No exercício de suas atividades, produz informações de efeito determinante as entidades, fisco, investidores, clientes, credores, administradores e demais usuários que tenham interesses nas informações ou elementos contábeis”. (RIBEIRO, 2018, p. 4).

Desta forma, segundo Ludícibus, et al (2010, p. 4), “a Contabilidade é um conjunto integrado de conceitos e normas para fornecer informações que devem ser moldadas às finalidades para as quais se destinam", ou seja, dados fornecidos de acordo com a necessidade e finalidade de aplicação para cada usuários.

Com a expertise fornecida pela Ciência da Contabilidade, o campo profissional contábil, proporciona amplamente áreas de atuação tais como: Analista, Auditor, Consultor financeiro, Perito, Cargos de gestão, Gerente Financeiro, Controller, entre outras.

O atual trabalho teve como campo de pesquisa a Perícia Contábil, que para Magalhães (2017, p. 12), "entende por um trabalho de notória especialização feito com o objetivo de obter prova ou opinião para orientar uma autoridade formal no julgamento de um fato, ou desfazer conflito de interesses de pessoas".

Ramo este que tem se destacado no atual cenário econômico-financeiro, por possuir um procedimento que exerce exame, vistoria e avaliação, utilizando de cálculos, na maior parte, sendo realizada por profissionais da área de Ciências Contábeis, que possuem conhecimento técnico e teórico.

A Perícia Contábil é um instrumento eficaz para o poder judiciário, para melhor compreensão do assunto trouxe estudo sobre abordagem de vários autores que conceituam a Perícia, dentre estes, Lopes (2018), que destaca como uma atividade concernente a exame realizado por profissional especialista, legalmente habilitado, destinado a verificar ou esclarecer determinado fato, apurar as causas motivadoras do mesmo, ou o estado, alegação de direitos ou a estimação da coisa que é objeto de litígio ou processo.

A perícia constituindo de uma tecnologia que tem o desígnio de explicar os fatos e diminuir as interrogações, seu uso para propiciar melhores condições de justiça para as partes envolvidas no processo, tal trabalho técnico pode estar presente em qualquer área, destacando-se a Perícia Contábil no presente artigo. 
Dispositivo que tem a função de trazer à deslinde a verdade sobre os fatos ou a opinião sobre algum assunto. O Código de Processo Civil (CPC) de 1939 já estabelecia vagas regras sobre perícia. Foi, contudo, em 1946, com o advento do Decreto-lei no 9.295/46 (que criou o Conselho Federal de Contabilidade e definiu as atribuições do contador), que se pôde dizer institucionalizada a Perícia Contábil no Brasil (MAGALHÃES, 2017).

Alusiva a prova pericial, segue conceituação da mesma, afim de tornar-se de mais claro seu uso. Mello (2016, p. 20), afirma que "é um meio de prova admitido na nossa legislação diferenciando-se das demais modalidades, principalmente em razão do emprego de conhecimento técnico-cientifico na realização."

O Conselho Federal de Contabilidade também traz as normas aprovadas referente a Perícia Contábil, esta Norma Brasileira de Contabilidade regida pela TP 01, NBC TP 01 (R1), que cataloga diversas informações técnicas aplicativas para os trabalhos em Perícia Contábil, no item 32 desta nota descreve a definição de planejamento do trabalho da perícia.

Para Hoog, (2014), a perícia tem por objeto a prova, sendo está a revelação da verdade, que é obtida sob a égide da biocontabilidade, ou seja, comprovar a verdade dos fatos ou atos declarados; aquilo sobre o qual incide um direito ou uma obrigação. Assim, o objeto e o objetivo, ambos têm a mesma definição, distinguindo apenas pela ocorrência, de demostrar a relevância dos fatos ou obrigação.

Conforme cita Crepaldi (2019) os trabalhos periciais servem de base para a obtenção das informações necessárias à elaboração do planejamento da perícia os documentos dos autos.

No que se refere as modalidades da perícia, a mesma divide-se em dois grupos, pode ocorrer nos campos judicial e extrajudicial.

Aplicando o conceito do autor Crepaldi (2019, p. 65): "A perícia Judicial é a requerida pelo juiz de direito e exercida sob a tutela do sistema judiciário brasileiro, já a perícia extrajudicial é aquela que não está sob a tutela da justiça. É dividida em três subgrupos: arbitral, oficial/estatal e voluntária".

Quanto às regras de exercício profissional de Perito Contábil as mesmas seguem Normas Profissionais Perícia Contábil que são disciplinadas pelas NBC's: NBC PP - do Perito Contábil - recentemente alterada NORMA BRASILEIRA DE CONTABILIDADE, NBC PP 01 (R1), DE 19 DE MARÇO DE 2020 que deu nova redação à NBC PP 01, que dispõe sobre Perito Contábil. 
Que devido à validade do novo Código de Processo Civil, foram ajustadas nomenclaturas; forma de cálculo dos honorários, desvinculando das horas técnicas; e os anexos, da NBC citada acima.

Outra Norma Técnica estabelece conceito doutrina, regras e procedimentos aplicados de Contabilidade, que dispõe sobre Perícia, ou seja, NBC TP 01, Norma Técnica de Perícia, que também teve sua redação atualizada, para NBC TP 01 (R1), em 19 DE MARÇO DE 2020, que dispõe sobre perícia contábil.

$\mathrm{O}$ art. 149 do Código de Processo Civil (CPC), trata-se de um profissional com formação superior que detém conhecimentos técnicos e/ou científicos que o tornam apto a auxiliar a Justiça quando é necessária a aplicação de suas habilidades para provar algum fato ou ato.

Em uma de suas obras, Crepaldi (2019), conceitua que o perito deve possuir conhecimentos técnicos, ter um aprimoramento cultural diversificado e ser especializado e aperfeiçoado em sua área de atuação. Assim, deve agir com conduta estritamente profissional, com aspectos éticos e imparcial, aplicando as técnicas sobre o assunto abordado.

Essencialmente o desígnio do laudo é oferecer uma a opinião técnica de um especialista sobre o contexto, elemento das discussões que deram causa à averiguação dos eventos, seja no campo da Justiça ou fora dela (ZANNA, 2007).

O laudo, segundo afirma Ornelas (2017) deve possuir algumas determinadas qualidades intrínsecas, tais como ser: completo, claro circunscrito ao objeto da perícia e fundamentado, com o intuito de esclarecer todas as dúvidas, estabelecidas nas questões determinadas pelo magistrado.

Assim nossa pesquisa apresenta o objetivo de demonstrar a percepção dos Magistrados de primeira instância na Comarca de Gurupi-TO, no que tange a relevância das Perícias técnicas realizadas por Peritos contadores nas demandas judiciais.

Acerca dos objetivos específicos busca-se levantar a área que apresenta maior dificuldade para a nomeação de Peritos Contábeis nas ações judiciais, verificar a área da Perícia Contábil que apresenta maior demanda na esfera Judicial e identificar se a Perícia Contábil possui verdadeira relevância para os juízes em casos reais.

\section{MATERIAIS E METODOS}

Neste presente artigo, considerando as particularidades da contabilidade, em relação aos objetivos foi exploratória. Quanto à abordagem da questão problemática, trata- 
se de pesquisa qualitativa. Baseou-se em estudo bibliográfico e pesquisa de campo mediante aplicação de questionários, aos Magistrados de Primeira Instância na Comarca de Gurupi-TO.

A pesquisa dividiu-se em quatro etapas: na fase inicial, apresentou caráter bibliográfico, sendo elaborado no período de março a junho de 2020 , com à formação do referencial teórico, que fundamentou a base teórica para a pesquisa, na segunda etapa, foi elaborado o instrumento de pesquisa e o trabalho foi submetido ao CEP etapa que ocorreu no período de 13 de agosto a 28 de setembro de 2020.

Já a terceira etapa onde aconteceu a pesquisa de campo, com a coleta de dados afim obter conhecimento detalhado para responder a problemática em estudo, com início em 05 a 20 de outubro/2020, através de e-mails enviados aos participantes com um questionário elaborado pela ferramenta Google Forms aos Magistrados de Primeira Instância na Comarca de Gurupi-TO.

Em sua quarta fase ocorreu a análise dos dados, após a coleta e recebimento do resultado dos questionários, para uma clareza no processo de análise de dados e interpretação das informações, esse processo, segundo os autores Prodanov e Freitas (2013, p. 130) "o critério dispõe-se a identificar se o estudo explana os procedimentos adotados para análise dos dados coletados durante a pesquisa."

Os critérios de inclusão e exclusão adotados na presente pesquisa, fora delimitado, com magistrados da Comarca de Gurupi, atuantes nas varas do Tribunal Regional Trabalho

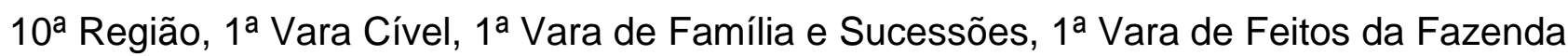
e Registros Públicos, 2ª Vara Cível 3ª Vara Cível e Justiça Federal de 1ํ Grau em Tocantins, que aceitou participar da pesquisa assinando o TCLE. Quanto as exclusões, foram excluídos aqueles que se abnegou de responderem os questionários.

Justifica assim o tamanho e a delimitação da nossa Amostra em 5 (cinco) Juízes, com objetivo de levantar a percepção dos Magistrados de primeira instância na Comarca de Gurupi-TO, no que tange a relevância das Perícias técnicas realizadas por Peritos contadores nas demandas judiciais,

Valendo-se do Procedimento metodológico, como instrumento que proporcionou a coleta de dados, o mesmo um questionário, que ao preencher sua primeira parte, escolheu até 3 (três) opções apresentadas, em segunda parte, o questionário em escala de likert, onde o respondente deu nota a cada pergunta em escala pré-determinada, com nota de 1 a 6 , onde 1 é concordo totalmente e 6 é não se aplica e com instrução de devolutiva das respostas do questionário. 
Sendo preponderante uma descrição dos procedimentos de análise dos dados que permite avaliar se os resultados obtidos, são - ou não - frutos de métodos e processos detalhados, para o tema proposto desta.

A análise dos dados conforme Soriano (2004, p. 243),

...segue o procedimento da utilização da informação consiste que são: síntese da informação, análise da informação, usando de diversos métodos como o descritivo, o dinâmico, o de correlação e o de conteúdo; síntese geral dos resultados.

Quanto aos aspectos éticos a pesquisa foi submetida CEP, sendo aprovada pelo Comitê de Ética e Pesquisa com Seres Humanos, conforme a resolução 466/2012 do Conselho Nacional de Saúde, com número do Certificado de Apresentação para Apreciação Ética (CAAE) sob o número 38199120.4.0000.5518, com data de aprovação 28 de setembro 2020.

\section{RESULTADOS E DISCUSSÃO}

A pandemia do coronavírus (Covid-19) mudou o cenário social, nos últimos meses no Brasil e no mundo, trouxe mudanças em vários sentidos à vida das pessoas. Com isso, um obstáculo, que devido a necessidade de entrevistar magistrados, fez-se necessário alteração da aplicação presencial do questionário, para modalidade online, devido a Pandemia, que requer distanciamento social como medidas de prevenção ao Covid-19.

O presente tópico apresenta os resultados e a análise dos dados da pesquisa, coletados através da plataforma Google Forms com envio de link via e-mail, ao respectivo público alvo, no nosso caso os magistrados.

Os resultados obtidos constituíram do retorno de $80 \%$ do público esperado a participar do estudo, em nossa Pesquisa de Campo, na coleta de dados, estruturada em um questionário com 7 (sete) questões de múltiplas escolhas e de seleção.

Com o resultado e discursão aqui exposto dispor-se a demonstrar a percepção dos Magistrados de primeira instância na Comarca de Gurupi-TO, no que tange a relevância das Perícias técnicas realizadas por Peritos contadores nas demandas judiciais.

A fim de comparar esta pesquisa, com outras já realizadas, em nível nacional, alusivos ao objeto desta deste artigo que também abordam o assunto principal: perícia contábil, perito contador e sua importância no judiciário:

Os juízes têm a total autonomia para escolher o profissional de sua confiança, que no caso da perícia contábil é o perito contador, que detém a responsabilidade de 
passar segurança suficiente ao magistrado para a tomada de decisão sobre uma questão da qual não retém conhecimento técnico suficiente para solucionar o problema, através do laudo elaborado por um especialista no assunto (GIACOMOZZI, 2015).

As representações abaixo ilustram os resultados encontrados:

Gráfico 1: Varas de atuação dos Magistrados

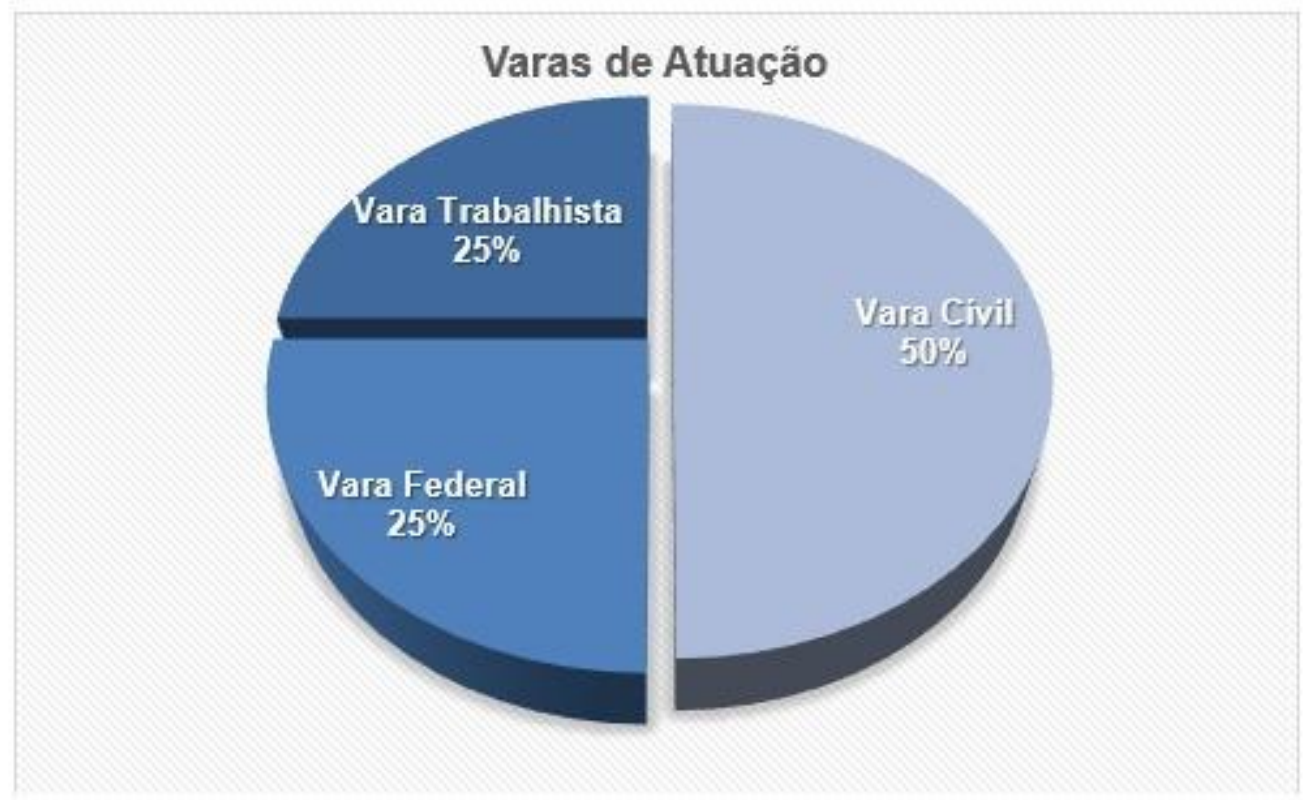

Fonte: Dados coletados entre os Magistrados de primeira instância na comarca de Gurupi-TO (2020).

Acima, exibindo as Varas de atuações dos magistrados, nosso público alvo, nas Comarcas já citadas anteriormente

De acordo com dados coletados, puderam ser identificados em relação ao campo de atuação da Perícia Contábil, aqueles que apresentam maior demanda na esfera Judicial, as opções segundo essas informações e demonstrado abaixo que são:

- Apuração de haveres;

- Revisão de contrato financeiro;

- Ações trabalhistas

- e Lucros cessantes.

Assim, as duas primeiras áreas citada acima, exibem mais da metade da demanda em perícia contábil, como pode ser entendido no gráfico 2. 
Gráfico 2: Maior demanda na esfera judicial

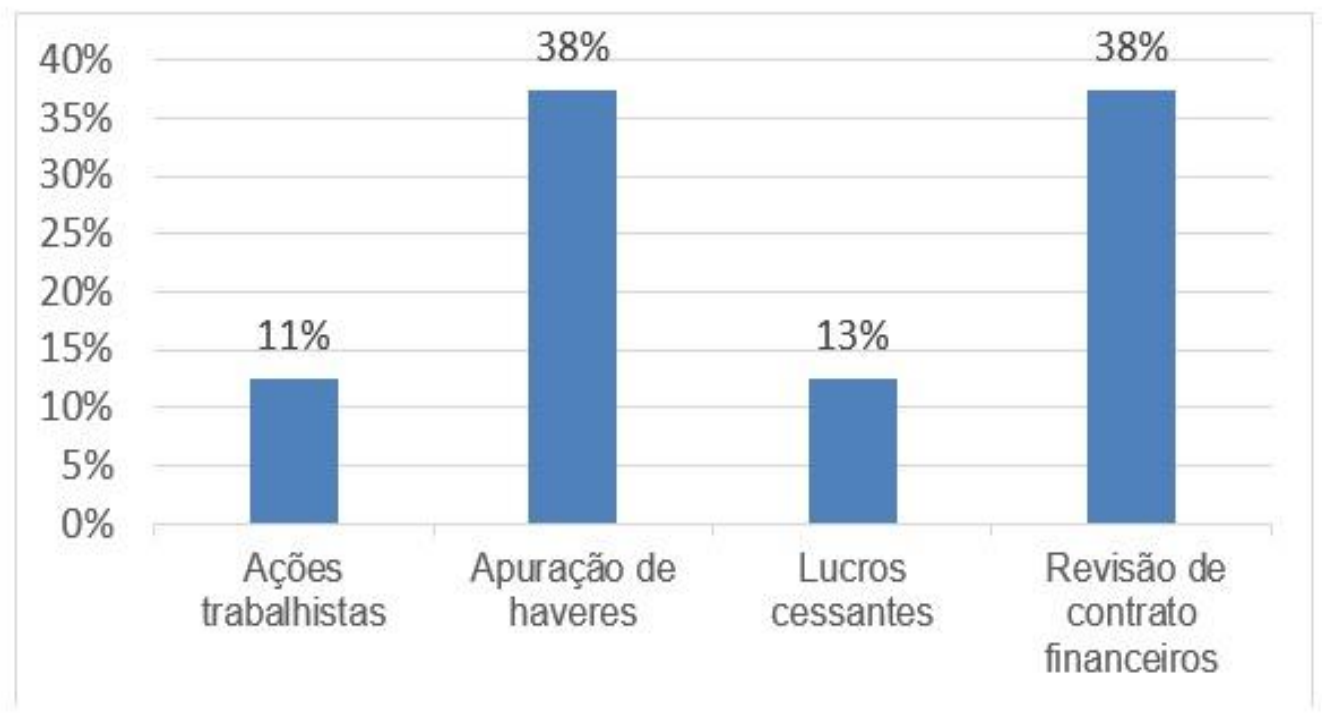

Fonte: Dados coletados entre os Magistrados de primeira instância na comarca de Gurupi-TO (2020).

No quesito prova e perito, não se pode negar o valor de prova que tem um parecer vigoroso, criterioso, criterioso, emitido por profissional de notória capacidade, mas, para que tenha tal qualidade, é preciso que seja inequívoco. (Sá, 2019, p. 88)

Gráfico 2.1: Área que apresenta maior dificuldade para a nomeação de Peritos Contábeis

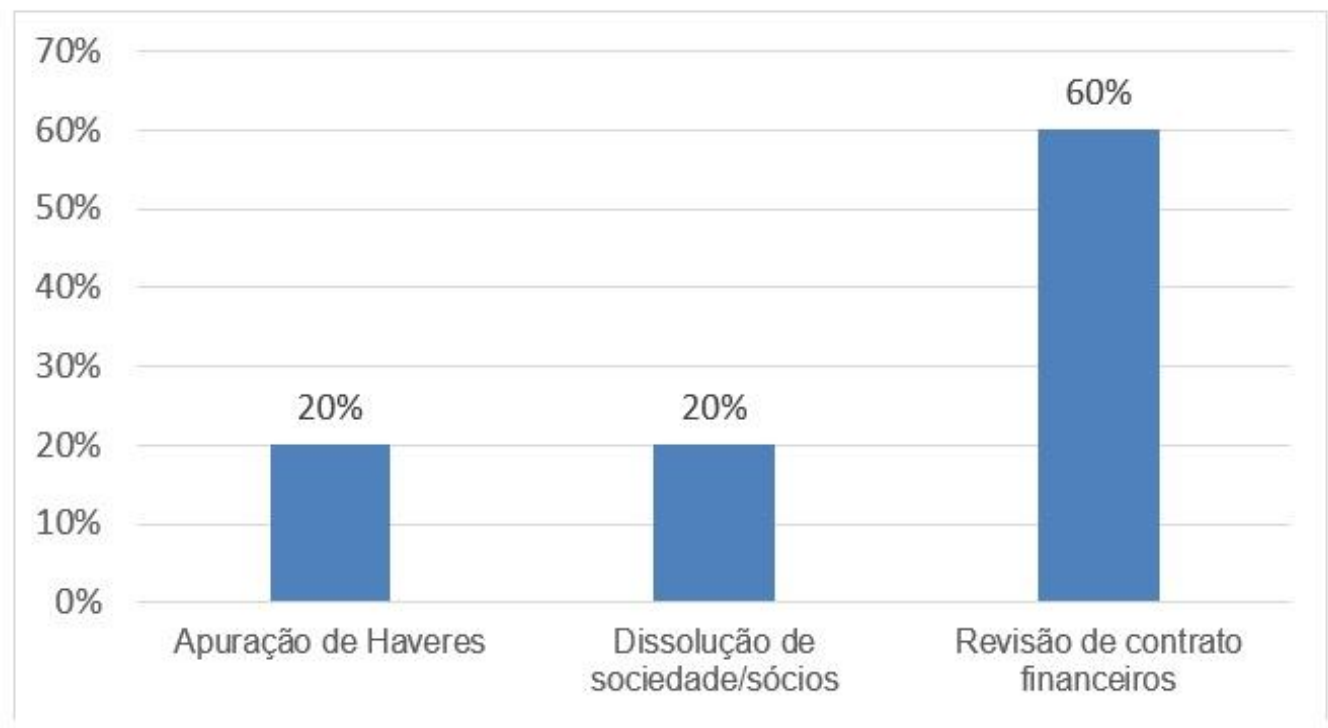

Fonte: Dados coletados entre os Magistrados de primeira instância na comarca de Gurupi-TO (2020).

Analisados quanto a área que apresentam maior dificuldade (Gráfico 2.1) para nomeação de Peritos Contábeis os mais mencionados dentre as opções citadas no questionário, foram as seguintes: 
- Apuração de haveres,

- Dissolução de sociedade/sócios,

- $\quad$ e Revisão de contrato financeiros.

Tais dificuldades, confirmam a carência de profissionais competentes que sejam capazes e forneçam informações que resultem nos desfechos de disputas solucionáveis, mas que exigem habilidade e capacidades de produzir, como descreve Ornelas (2017, p.26) sobre tal aptidão na área requerida, gerando um "levantamento e apuração de contas de qualquer organização."

Ainda sobre o gráfico acima, salienta-se que todas as áreas apresentadas possuem algum tipo de dificuldade quanto às nomeações, todavia destacam-se uma área pouca explorada, citada por um dos entrevistados, que nos deu retorno via e-mail, informando que sua área de maior dificuldade quanto a nomeação de Perito é na área de cálculo atuarial, e que a mesma não foi citada na nossa pesquisa.

Segundo vemos no Gráfico 3, aproximadamente $100 \%$ dos entrevistados Concordam Parcialmente que os laudos são desenvolvidos pelo Perito Contábil em tempo hábil e também atendem as expectativas dos magistrados.

Gráfico 3: Os laudos desenvolvidos pelo Perito Contábil atualmente atendem inteiramente vossas expectativas.

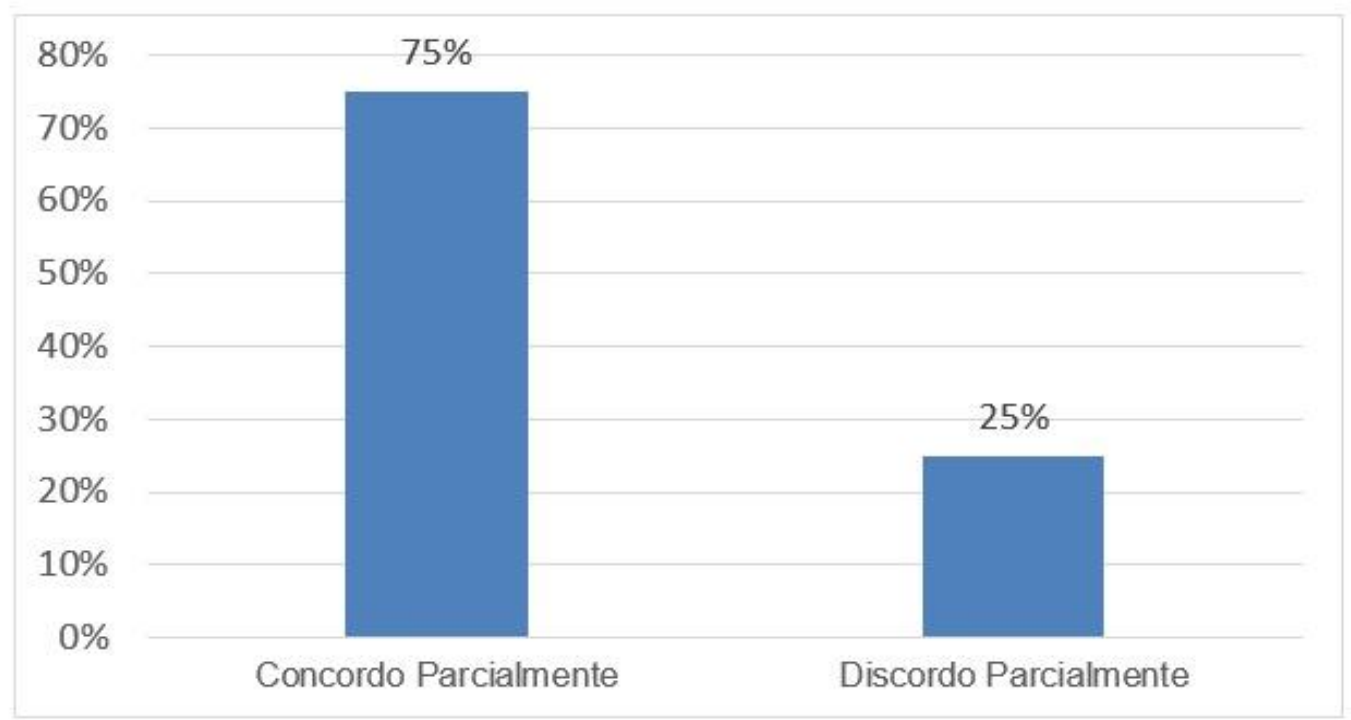

Fonte: Dados coletados entre os Magistrados de primeira instância na comarca de Gurupi-TO (2020).

De acordo com o Gráfico 4, quando questionados em relação aos laudos emitidos pelos peritos, ser uma ferramenta-chave para elaborar da sentença metade Concorda Totalmente, enquanto outra metade contrapôs que não aplica. 
Gráfico 4: O laudo é uma ferramenta-chave para a elaboração da sentença

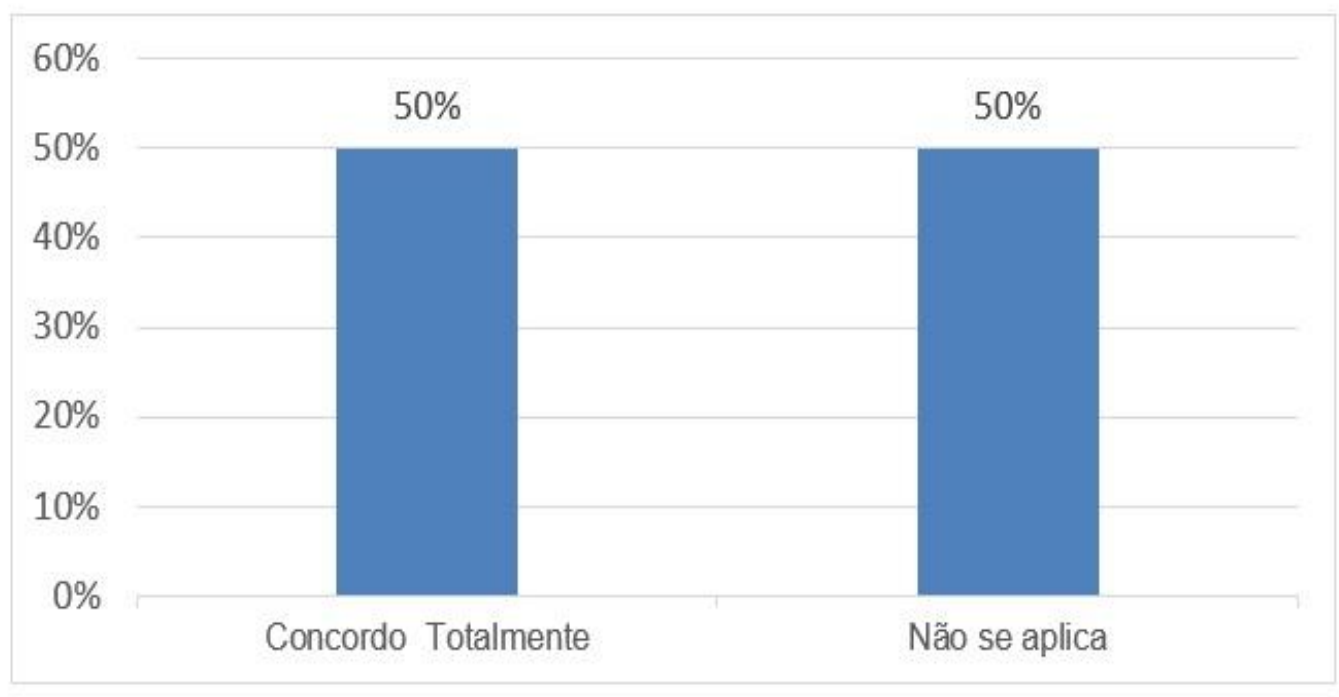

Fonte: Dados coletados entre os Magistrados de primeira instância na comarca de Gurupi-TO (2020).

Aclarando, quanto a definição de laudo para Hoog (2015, p. 39), "é, de fato, um pronunciamento ou manifestação de um especialista, ou seja, o que ele entende sobre uma questão ou várias, que se submetem a sua apreciação."

Gráfico 5: Em sua percepção o laudo Pericial é insuficiente, pois poderia haver melhoria para o desfecho.

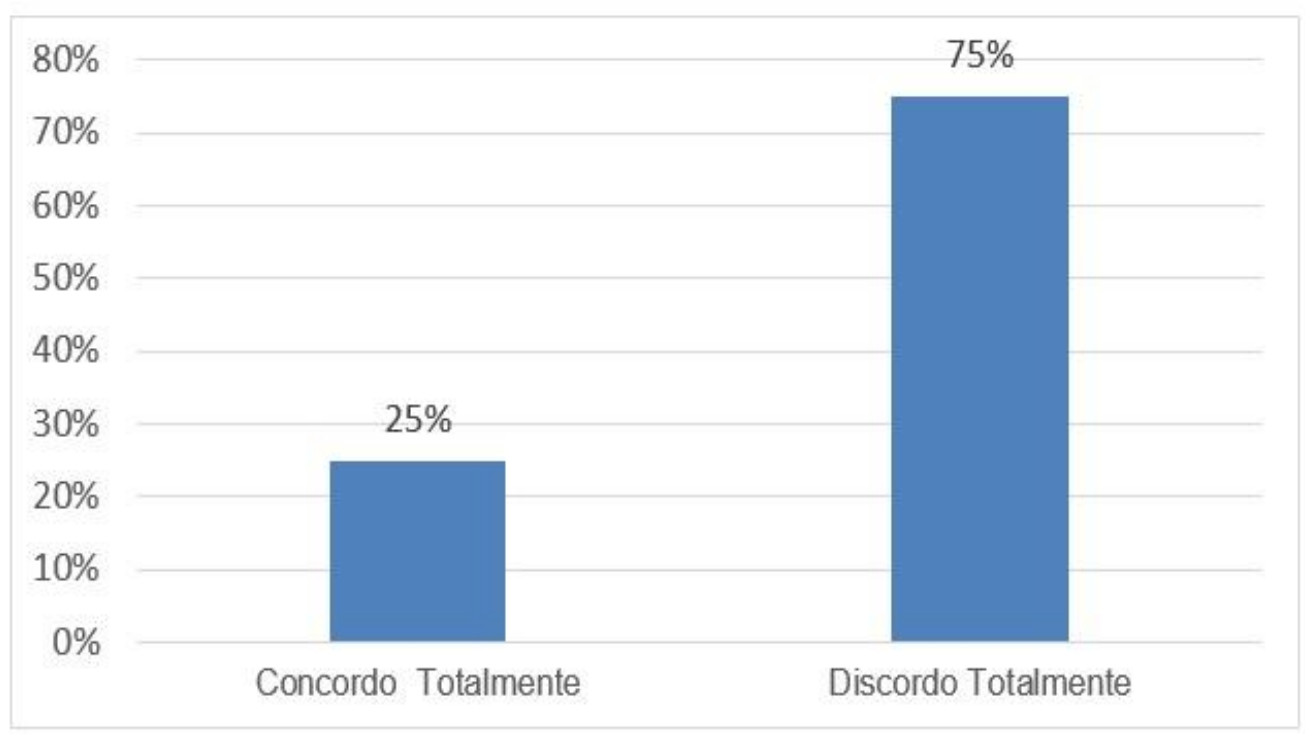

Fonte: Dados coletados entre os Magistrados de primeira instância na comarca de Gurupi-TO (2020).

Assim no Gráfico 5, aproximadamente todos discordam totalmente que os laudos emitidos pelos peritos são insuficientes ou poderiam melhorar, ou seja são suficientes e 
adequados as solicitações dos magistrados. O que nos leva a afirmativa do escritor Hoog (2015, p.03), "Quando precisamos de uma opinião válida, competente, de um entendedor, buscamos um Perito."

As informações coletadas comprovaram no Gráfico 6, que há necessidade de retrabalho em alguns casos, sendo confirmado com metade dos entrevistados que ver necessidade de serem refeitos alguns laudos Periciais.

Gráfico 6: Ocorre necessidade de retrabalho do laudo Pericial

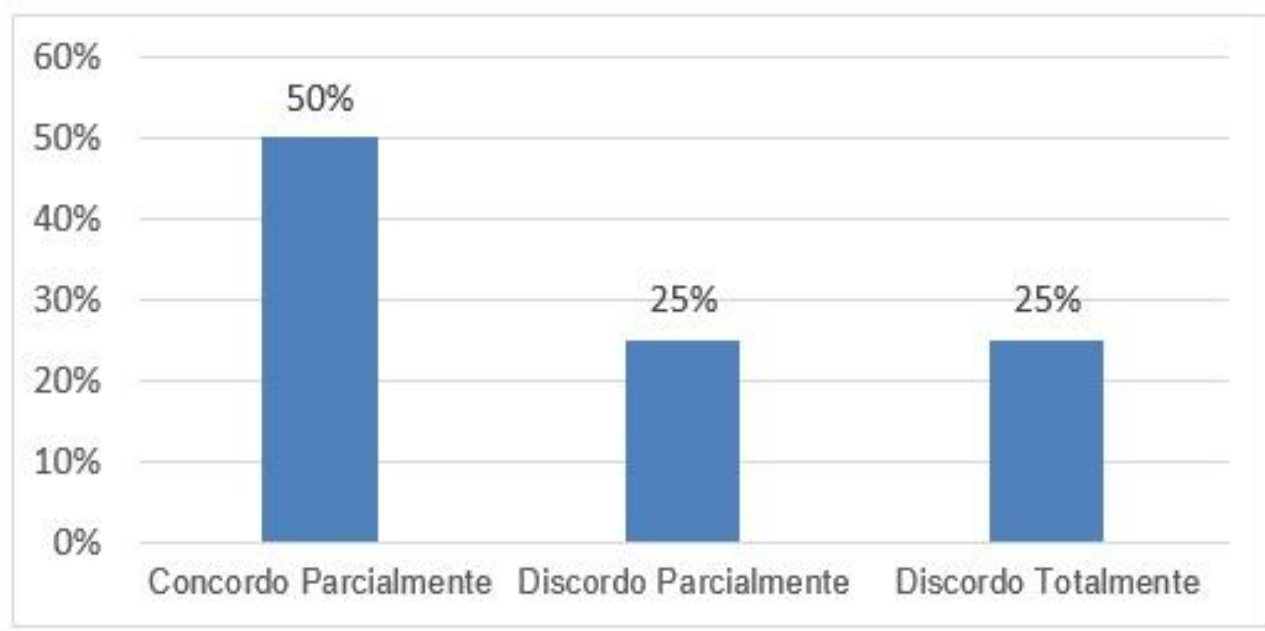

Fonte: Dados coletados entre os Magistrados de primeira instância na comarca de Gurupi-TO (2020).

No que se refere ao prazo no Gráfico 7, as entregas dos laudos solicitados dos magistrados metade Concordam Parcialmente que são entregues em tempo hábil outros, já a outra metade dos entrevistados se dividiu que não são entregues em tempo hábeis.

Baseando-se em seus diretos e deveres como perito, exposto como sua obrigação no cumprimento de prazo, descritas no CPC deixar claro sobre a abordagem do gráfico a seguir:

Segundo o CPC art. 157. "O perito tem o dever de cumprir o oficio no prazo que lhe designar o juiz, empregando toda sua diligência, podendo escusar-se do encargo alegando motivo legitimo." 
Gráfico 7: Os laudos são entregues em tempo hábil

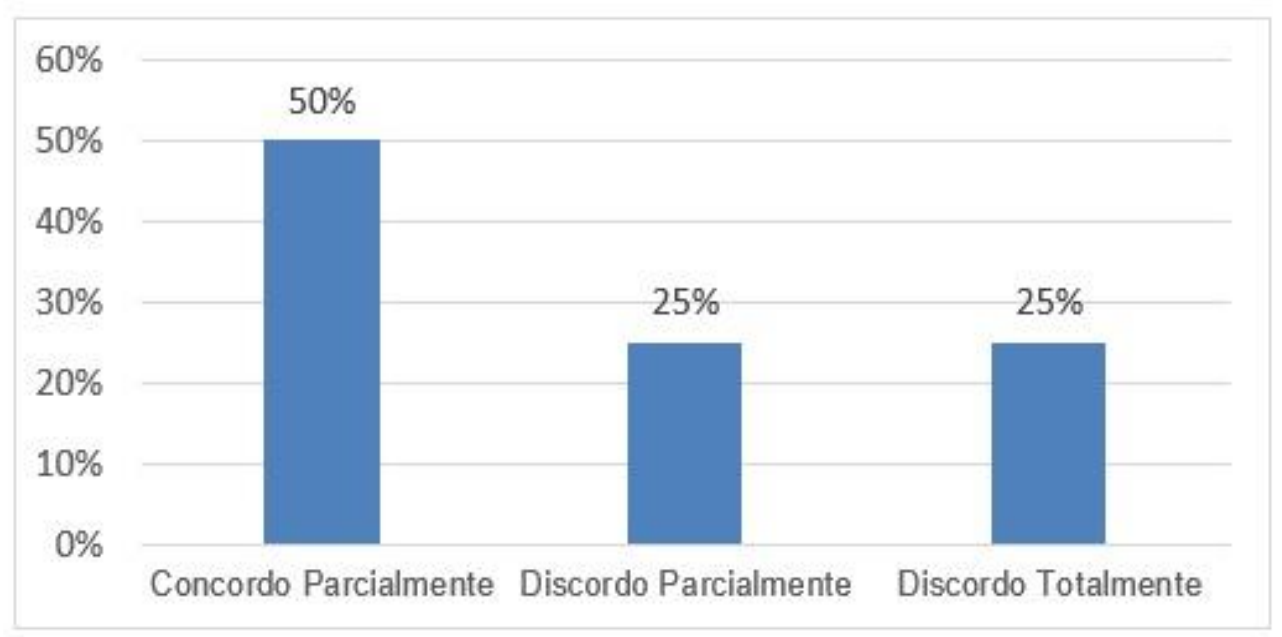

Fonte: Dados coletados entre os Magistrados de primeira instância na comarca de Gurupi-TO (2020).

Os laudos se fazem imprescindíveis para a execução dos meios legais de solução de litígios, quando o juiz aplica o direito, com o objetivo de sentenciar sua decisão ou conciliar as partes envolvidas, é um processo argumentativo de fundamentos, ou seja, a verdade em juízo é motivada por uma decisão. Usando-a através da avaliação das provas os fatos são descritos e expostos de forma clara, apresentando a veracidade dos fatos ocorridos, conforme as autoras, Zanardelli e Silva (2018, p. 5), acrescentam.

Do mesmo modo aprimoramos entre resultados e discursão ressaltou que a função da perícia contábil em demandas judiciais, tem sua importância, eles emitiram o laudo solicitado, evidenciando habilidades e conhecimentos específicos capazes de auxiliar no deslinde judicial com conhecimento que o magistrado não domina.

Em resumo os dados coletados resultaram na seguinte interpretação: os laudos são elaborados para atender a expectativa dos magistrados e atendem, como ferramentachave na liquidação de sentenças, são insuficientes, alguns têm necessidades de retrabalho, ou seja, uma nova perícia, e no geral são entregues em tempo hábil.

\section{CONSIDERAÇÕES FINAIS}

Os resultados desta pesquisa afirmam a importância de um profissional, tal como o Perito Contador, com aptidão, destreza e conhecimentos peculiares que possa elucidar questões em processo que requer perito, para o desfecho de questões judiciais.

Quanto nosso objetivo em identificar a relevância da Pericial contábil em casos reais, diante das devolutivas dos magistrados, ficou evidenciada, nas varas onde a pesquisa fora 
aplicada, sua relevância e sua efetividade em liquidações de sentenças, deslinde judiciais, frente às demandas judiciais nas diversas áreas, seja comercial, trabalhistas e financeiras.

A pesquisa apresentou as áreas que exibe maior dificuldade para a nomeação de Peritos Contábeis nas ações judiciais que são: Apuração de Haveres, Dissolução de sociedade/sócios e Revisão de contratos financeiros.

As Ações trabalhistas, Apuração de haveres, Lucros cessantes e Revisão de contrato financeiro são as áreas com maior litígio quanto à necessidade de Perícias contábeis segundo os dados coletados em nossas pesquisas.

A pesquisa se mostrou relevante devido a tratar um assunto ainda pouco explorado, apresenta caráter inovador de relevância acadêmica e social. Assim está pesquisa poderá contribuir para estímulo a explanação quanto ao tema deste artigo, no sentido de conhecer ou desenvolver novos profissionais, já que o tema é tão pouco explorado a nível regional e estadual.

Prova de que o tema é pouco explorado, temos a Perícia Atuarial, que não há profissionais atuantes no Estado, havendo necessidades de cálculos atuariais em processo nas Varas da cidade, é necessário buscar em outros estados tais profissionais, pois até o presente momento não há Peritos Contábeis, hábeis no assunto, na cidade de Gurupi ou no estado do Tocantins.

\section{REFERÉNCIAS}

BRASIL. Código de Processo Civil (2015). Código de Processo Civil Brasileiro. Brasília, DF: Senado, 2015. Disponível em: <http://www.planalto.gov.br/ccivil_03/_ato20152018/2015/lei/l13105.htm > Acesso em: 01 Set. 2020.

CONSELHO FEDERAL DE CONTABILIDADE (2015). NORMAS BRASILEIRAS DE CONTABILIDADE: NBC PP 01 - Perito Contábil. De 27 de Fevereiro de 2015. Disponível em: <http://www1.cfc.org.br/sisweb/sre/detalhes_sre.aspx?codigo=2015/NBCPP01> Acesso em: 10 abril. 2020.

CONSELHO FEDERAL DE CONTABILIDADE (2020). NORMAS BRASILEIRAS DE CONTABILIDADE: NBC TP 01 (R1) - Perícia Contábil. De 19 de Março de 2020. Disponível em:<http://www1.cfc.org.br/sisweb/sre/detalhes_sre.aspx?codigo=2015/NBCTP01(R1)> Acesso em: 10 abril de 2020.

CREPALDI, Silvio Aparecido. Manual de Perícia Contábil. 1aㅡ ed. São Paulo: Saraiva Educação: 2019.

GIACOMOZZI, I. A. Perícia Contábil, tema atual de alta relevância para o judiciário. Trabalho de conclusão de curso de especialização em Direito Tributário e Perícia Tributária 
do Centro Universitário Católica de Santa Catarina. 2015. Retirado de < http://app.catolicasc.org.br/imagens_biblio/000099/00009973.pdf >.

HOOG, Wilson Alberto Zappa. Introdução à Perícia, Auditoria \& Consultoria Contábil: Uma Tricotomia Contábil. 4ª ed. Revista e Atualizada. Curitiba: Juruá: 2014.

IUDÍCIBUS, Sérgio de. Contabilidade Introdutória: 2ª ed. São Paulo: Atlas, 2010.

LOPES, André Charone Tavares Lopes. Perícia Contábil. Sem Enrolação. 1ª ed. São Paulo: Editora Biblioteca: 2018.

MAGALHAES, Antônio de Deus Farias. Perícia Contábil. 8ª ed. São Paulo: Atlas, 2017.

MELLO, Paulo Cordeiro de. Perícia Contábil. 2ª ed. Atualizada: São Paulo: Editora Senac: 2016.

ORNELAS, M. M. G. Perícia Contábil. 6ª ed. São Paulo: Atlas: 2017.

PRODANOV, C. C.; FREITAS, E. C. Metodologia do trabalho científico: métodos e técnicas da pesquisa e do trabalho acadêmico. $2^{\mathrm{a}}$ ed. Novo Hamburgo: Feevale, 2013.

RIBEIRO, Osni Moura. Contabilidade Geral. $10^{\text {a }}$ ed. Saraiva. São Paulo: 2018.

ZANARDELLI, Juliana; SILVA, Luane. A Importância do Perito Contábil nas Decisões Judiciais. Anais do Conic-Semesp / Volume 6, 2018 - UNIP - Universidade Paulista.

ZANNA, Remo Dalla. Prática de Perícia Contábil. 2ª ed. São Paulo: IOB Thomson: 2007. 